\title{
Modeling Structural Coordination and Ligand Binding in Zinc Proteins with a Polarizable Potential
}

\author{
Jiajing Zhang, ${ }^{\dagger}$ Wei Yang, ${ }^{\ddagger} \S$ Jean-Philip Piquemal, ${ }^{\|, \perp}$ and Pengyu Ren*, ${ }^{\dagger}$ \\ ${ }^{\dagger}$ Department of Biomedical Engineering, The University of Texas at Austin, Texas 78712, United States \\ ${ }^{\ddagger}$ The Institute of Molecular Biophysics and ${ }^{\S}$ Department of Chemistry and Biochemistry, Florida State University, Tallahassee, \\ Florida 32306, United States \\ "UPMC Univ. Paris 06, UMR 7616, Laboratoire de Chimie Théorique, case courrier 137, 4 place Jussieu, F-75005, Paris, France \\ ${ }^{\perp}$ CNRS, UMR 7616, Laboratoire de Chimie Théorique, case courrier 137, 4 place Jussieu, F-75005, Paris, France
}

Supporting Information

ABSTRACT: As the second most abundant cation in the human body, zinc is vital for the structures and functions of many proteins. Zinc-containing matrix metalloproteinases (MMPs) have been widely investigated as potential drug targets in a range of diseases ranging from cardiovascular disorders to cancers. However, it remains a challenge in theoretical studies to treat zinc in proteins with classical mechanics. In this study, we examined $\mathrm{Zn}^{2+}$ coordination with organic compounds and protein side chains using a polarizable atomic multipole-based electrostatic model. We find that the polarization effect plays a determining role in $\mathrm{Zn}^{2+}$ coordination geometry in both matrix metalloproteinase (MMP) complexes and zinc-finger proteins. In addition, the relative binding free energies of selected inhibitors binding with MMP13 have been estimated and compared with experimental results. While not directly interacting with the small molecule inhibitors, the permanent and polarizing field of $\mathrm{Zn}^{2+}$ exerts a strong influence on the relative affinities of the ligands. The simulation results also reveal that the polarization effect on binding is ligand-dependent and thus difficult to incorporate into fixed-charge models implicitly.

\section{INTRODUCTION}

One third of all proteins contain metal ions as their integral parts. ${ }^{1}$ The metal ions in these protein complexes serve essential biological functions, from organizing the secondary or tertiary structure, facilitating protein-ligand interactions, to directly participating in catalytic activities. Many metalloproteins, similar to the ion channels, recognize and associate with only specific types of ions against a solution of various ions of similar properties (e.g., charge and size). For example, calmodulin, involved in signal transduction, DNA synthesis, and cell division, undergoes significant conformational changes upon binding to $\mathrm{Ca}^{2+} ;{ }^{2}$ protein kinases and ATPase require $\mathrm{Mg}^{2+}$ in coordination with ATP to facilitate phosphoryl transfer. ${ }^{3,4}$ Metalloenzymes, such as alcohol dehyrogenase, carboxypeptidase, thermolysin, and matrix metalloproteinases (MMPs), rely on $\mathrm{Zn}^{2+}$ for their catalytic activities. ${ }^{5}$ As the second most abundant cation in the human body, ${ }^{6} \mathrm{Zn}$ has important biological implications and is involved in the survival and pathogenesis of many viruses, including HIV, hepatitis, herpes simplex, Rubella, and influenza. ${ }^{7-11}$

In aqueous solution, it is well established that $\mathrm{Zn}^{2+}$ has a coordination number of six and forms an octahedral structure with water. When binding in the protein complexes, a tetrahedral arrangement with the surrounding amino acid residues is often observed, although $\mathrm{Zn}^{2+}$ can also exist in a fiveor a six-coordinated complex. In protein, $\mathrm{Zn}^{2+}$ can serve either a catalytic role, by participating directly in chemical catalysis, or a structural role solely to maintain protein structure and stability. ${ }^{12}$ Analysis of protein X-ray structures shows that, among 126 structural proteins, a majority of the zinc sites
(82\%) are 4-coordinated, only $14 \%$ are 5-coordinated, and $4 \%$ are 6-coordinated. Of 147 catalytic binding proteins, $58 \%$ are $4-$ coordinated, $31 \%$ are 5-coordinated, and $11 \%$ are 6 coordinated. ${ }^{13}$ Therefore, tetrahedral coordination is dominant in proteins, although a significant amount of zinc ions display higher coordination numbers. Common ligands for the zinc ion include histidine, aspartate or glutamate, and cysteine, in a variety of combinations. The flexibility in the ligand choices and coordination geometries leads to diverse $\mathrm{Zn}^{2+}$ binding sites in zinc metalloenzymes, rendering possible a range of important biological roles, such as catalytic, coactive, and structural functions. $^{14}$

A computational study of zinc ions embedded in a protein active site has been a long-standing challenge. While Quantum Mechanics ${ }^{15}$ or combined Quantum Mechanics/Molecular Mechanics methods ${ }^{16,17}$ have been applied to investigate zinccontaining molecular systems, the computational cost of high level $a b$ initio calculations makes it difficult to tackle complex configurational space or long-time dynamics. On the other hand, classical mechanics treatment of $\mathrm{Zn}^{2+}$ is problematic. The strong local electrostatic field and induction effect ${ }^{18}$ pose challenges for the traditional fixed-charge molecular mechanics $^{19-21}$ and quantum chemistry methods ${ }^{22,23}$ to model zinc ions in biomolecules.

Two types of approaches have been implemented in a fixedcharge force field: nonbonded and bonded models. The nonbonded model presented by Stote and Karplus ${ }^{24}$ is widely

Received: November 11, 2011

Published: February 13, 2012 
used due to its simplicity and efficiency in the investigation of the structure, dynamics, and energetics of zinc-containing proteins. For example, Donini and Kollman reported studies on inhibitors binding to matrix metalloproteinases based on such a nonbonded description for $\mathrm{Zn}^{2+} \cdot{ }^{20}$ However, it is generally believed that treating zinc metal in a nonbonded fashion leads to an overly strong preference for octahedral coordination, and sometimes the zinc ion even escapes from the coordination sphere. It has also been reported that the nonbonded model is not able to properly describe the coordination number and energy at the same time. ${ }^{25}$ Many have attempted to use artificial bonds between ion and ligand atoms to fix the geometry for the purposes of modeling ion-ligand interactions, which is referred to as the bonded model. ${ }^{26-28}$ A semibonded model with tetrahedral charge dummies around zinc has also been proposed. $^{29}$ By placing four cationic dummy atoms tetrahedrally around the zinc nucleus, the orientation requirement for the zinc coordinates is imposed all the time during the simulation. The extra charge sites however give rise to unphysical permanent dipole and quadrupole moments to the $\mathrm{Zn}^{2+}$. These bonded or semibonded models and their variant methods freeze the specific zinc coordination to the surroundings, which will likely cause artifacts on the ligand conformational sampling and dynamics. The inability to model zinc has been a hindrance to understanding the versatile functions of $\mathrm{Zn}^{2+}$ and metalloenzymes, given that the variability in $\mathrm{Zn}^{2+}$ coordination may be coupled with enzyme function at different stages of the reaction. ${ }^{6}$ The lack of charge transfer and explicit polarizability can result in poor accuracy for the association energies. ${ }^{30}$ Classical nonpolarizable force fields are inherently unsuitable for describing flexible zinc coordination.

Polarizable potentials hold promise as they explicitly account for polarization and even charge-transfer effects. SIBFA was one of the first potentials developed to model $\mathrm{Zn}$ interaction with organic and biological molecules by rigorously incorporating polarization, charge transfer, penetration, and other effects. ${ }^{31-39}$ Gresh reported the very first attempt to introduce an explicit charge transfer energy term in $\mathrm{Zn}^{2+}$ modeling and this work systematically monitored the distal and angular dependencies against quantum chemistry energy decomposition in various $\mathrm{Zn}^{2+}$ ligand complexes. ${ }^{33} \mathrm{~A}$ critical feature of charge transfer effect relates to its nonadditive behavior in polyligated complexes, which was monitored against quantum chemistry computations by Tiraboschi et al. ${ }^{36,37}$ The penetration effect was also introduced for $\mathrm{Zn}$ by Gresh and co-workers in their subsequent work. ${ }^{32}$ The applications of SIBFA to model the complexes of inhibitors to a Zn-metalloenzyme, thermolysin, were initiated early in 1997-1998, ${ }^{34,35}$ followed by applications to $\beta$-lactamase, ${ }^{38,39} \mathrm{Zn}$-fingers, ${ }^{40}$ and phosphomannoisomerase. $^{41,42}$ Sakharov and Lim also developed a model which reproduced the experimentally observed tetrahedral structures of $\mathrm{Cys}_{2} \mathrm{His}_{2}$ and $\mathrm{Cys}_{4}$ Zn-binding sites in proteins. ${ }^{43}$ The treatment by Sakharov and Lim simply introduced distancedependent partial charges on zinc without actually accounting for the second order charge-transfer effect. It is interesting to note that reduced partial charges lead to less favorable Coulombic interactions, opposite of what one expects from a charge-transfer effect.

Previously, we developed a polarizable multipole-based model for $\mathrm{Zn}^{2+}$ in a water environment. ${ }^{18}$ In this study, we are extending the polarizable model to investigate zinc binding with organic molecules and proteins. Three molecules, the acetate anion, the methanethiol anion $\left(\mathrm{CH}_{3} \mathrm{~S}^{-}\right)$, and imidazole, were selected to mimic the side chains of typical $\mathrm{Zn}^{2+}$ interacting ligands, Asp, Cys, and His. Two zinc enzyme systems with different coordination ligands (Asp, His, Cys, water) have been examined using MD simulations (Figure 2): system $\mathrm{A}$ is a zinc-finger with three 4-fold coordinated zinc structural sites, and system $\mathrm{B}$ is a matrix metalloproteinase (MMP) complex with two 4-fold coordinated zinc sites, one catalytic and the other structural zinc.

The $\mathrm{Cys}_{2} \mathrm{His}_{2}$-type zinc-finger protein consists of highly conserved zinc finger domains where each zinc ion is coordinated by two cysteines and two histidines. Each domain consists of two $\beta$ strands, one $\alpha$ helix, and a hairpin structure. Three residues located at the $\alpha$ helices in each finger interact with three nucleotide bases of the DNA, typically making contacts with contiguous three base pair recognition sites. Such a direct recognition mode to DNA makes zinc finger proteins an ideal scaffold for designing proteins that can recognize the predetermined DNA sequences specifically. ${ }^{44}$ During the zincfinger protein folding process, zinc ions play a crucial role by binding to the peptides first, then directing the folding and stabilizing the $\beta$-hairpin and $\alpha$-helix as suggested by Li et al. ${ }^{45}$

The other $\mathrm{Zn}$-containing protein investigated here is MMP, which belongs to a family of zinc-dependent endopeptidases related to the physiological homeostasis of the extracellular matrix. Abnormal expression of MMPs has been implicated in a number of pathological conditions such as metastasis, angiogenesis, osteoarthritis, rheumathoid arthritis, and cardiovascular diseases. The development of selective and potent inhibitors to MMPs is a topic of considerable interest. ${ }^{46-50} \mathrm{~A}$ number of computational studies of inhibitors binding to MMPs have been reported. ${ }^{19,20,48,51}$ A majority of available MMP inhibitors are zinc chelating compounds containing zinc binding groups $(\mathrm{ZBG})$, such as hydroxamate $\left(\mathrm{CONH}-\mathrm{O}^{-}\right)$, carboxylate $\left(\mathrm{COO}^{-}\right)$, thiolate $\left(\mathrm{S}^{-}\right)$, or phosphinate $\left(\mathrm{PO}_{2}{ }^{-}\right) \cdot{ }^{52}$ Unfortunately, these inhibitors are often found to be biologically labile, lacking selectivity, or having toxic side effects. ${ }^{53}$ Considerable efforts have also been made to develop nonzinc chelating compounds that lead to inhibitors with specificity to certain MMP subtypes. ${ }^{54,55}$

\section{COMPUTATIONAL METHODS}

The Polarizable Force Field and Parametrization. In the AMOEBA force field, permanent atomic multipoles up to quadrupoles are used to describe electrostatic interactions. The polarization effect is explicitly accounted for by incorporating dipole induction in a self-consistent manner. ${ }^{56}$ A buffered 14-7 potential is used to describe the repulsion-dispersion interactions between pairs of nonbonded atoms. ${ }^{57}$ Parameters for all proteins and existing small molecules involved in this study were taken from the AMOEBA force field. ${ }^{58}$ Previously, the AMOEBA polarizable multipole based force field has been applied to study water, ${ }^{59,60}$ monovalent and divalent ions, ${ }^{18,61-63}$ organic molecules and peptides, ${ }^{56,64,65}$ proteinligand binding prediction, ${ }^{6,67}$ and computational X-ray crystallography ${ }^{68-70}$ with very encouraging success. A number of independent studies on ions ${ }^{71-76}$ and peptides using AMOEBA also demonstrated the improvements and advantages offered by the polarizable force field. ${ }^{77-80}$

$\mathrm{Zn}^{2+}$ electrostatic parameters include a point charge $(+2)$ and an atomic polarizability. ${ }^{18}$ In the AMOEBA force field, Thole damping is achieved by the screening of pairwise atomic multipole interactions and is equivalent to replacing a point 
multipole moment with a smear charge distribution. The damping function for charges is given by functional form ${ }^{81}$

$$
\rho=\frac{3 a}{4 \pi} \exp \left(-a u^{3}\right)
$$

where $u=r_{i j} /\left(\alpha_{i} \alpha_{j}\right)^{1 / 6}$ is the effective distance as a function of linear separation $r_{i j}$ and the atomic polarizabilities of sites $i\left(\alpha_{i}\right)$ and $j\left(\alpha_{j}\right)$. The coefficient $a$ is the dimensionless width of the smeared charge distribution and controls the damping strength. The corresponding damping functions for charge, dipole, and quadrupole interactions were reported previously. ${ }^{59}$ A single transferable isotropic polarizability for each common chemical element was derived by fitting to experimental polarizabilities of a set of representative organic molecules. Except for the aromatic atoms and atoms with formal charges (details below), the atomic polarizabilities as originally suggested by Thole were adopted in the AMOEBA force field, i.e., $1.334 \AA^{3}$ for carbon, $0.496 \AA^{3}$ for hydrogen, $1.073 \AA^{3}$ for nitrogen, and $0.837 \AA^{3}$ for oxygen (Table 2). The parameters for $\mathrm{Zn}$ and water were published previously ${ }^{18}$ and are used in this study.

The $a b$ initio calculation of the molecular polarizability tensor of three model compounds was performed at the level of MP2/ $6-31++G(2 d, 2 p)$ (see Table 1$)$. These molecular polarizability

Table 1. Comparison of Molecular Polarizabilities $\left(\AA^{3}\right)$ from ab Initio Quantum Mechanical, AMOEBA Polarizable Model Prediction, and Experimental Measurement

\begin{tabular}{|c|c|c|c|c|}
\hline & & $\begin{array}{c}a b \\
\text { initio }^{a}\end{array}$ & AMOEBA & other exptl or calcd \\
\hline \multirow[t]{4}{*}{$\mathrm{CH}_{3} \mathrm{COO}^{-}$} & $\alpha_{x x}$ & 7.12 & 6.09 & $7.34^{b}$ \\
\hline & $\alpha_{y y}$ & 6.95 & 5.71 & $7.49^{b}$ \\
\hline & $\alpha_{z z}$ & 4.58 & 4.47 & $4.91^{b}$ \\
\hline & $\alpha_{\text {total }}$ & 6.21 & 5.42 & $6.58^{b}$ \\
\hline \multirow[t]{4}{*}{$\mathrm{CH}_{3} \mathrm{~S}^{-}$} & $\alpha_{x x}$ & 6.97 & 5.34 & \\
\hline & $\alpha_{y y}$ & 6.97 & 5.34 & \\
\hline & $\alpha_{z z}$ & 8.42 & 7.14 & \\
\hline & $\alpha_{\text {total }}$ & 7.45 & 5.94 & $4.3 j^{c} 4.4 j^{c} 5.5 j^{c} 6.7^{c}$ \\
\hline \multirow[t]{4}{*}{$\mathrm{C}_{3} \mathrm{~N}_{2} \mathrm{H}_{4}$ (imidazole) } & $\alpha_{x x}$ & 8.09 & 9.44 & $9.6^{d}$ \\
\hline & $\alpha_{y y}$ & 7.97 & 8.81 & $8.6^{d}$ \\
\hline & $\alpha_{z z}$ & 4.88 & 5.39 & $6.6^{d}$ \\
\hline & $\alpha_{\text {total }}$ & 6.98 & 7.88 & $8.24 ;^{d} 7.5^{e}$ \\
\hline
\end{tabular}

${ }^{a}$ Calculated at the level of MP2/6-311++G(2d,2p). ${ }^{b}$ Calculation from ref $104 .{ }^{c}$ Calculation from ref $105 .{ }^{d}$ Experimental measurement from ref $106 .{ }^{e}$ Ref 107.

tensor values were used to verify and refine the atomic polarizability of aromatic atoms $(\mathrm{C}, \mathrm{N}$, and $\mathrm{H})$ and atoms with formal charges $\left(\mathrm{O}^{-}\right.$and $\left.\mathrm{S}^{-}\right)$. The final values of standard and adjusted atomic polarizabilities are compared in Table 2 .

Permanent atomic multipole parameters of the charged model compounds, the acetate anion $\left(\mathrm{COO}^{-}\right)$, the methanethiol anion $\left(\mathrm{CH}_{3} \mathrm{~S}^{-}\right)$, and imidazole, were derived in this study from $a b$ initio $\mathrm{QM}$ calculations. Specifically, the permanent multipole moments were derived using the original Distributed Multipole Analysis (DMA) method from the density matrix output at the level of MP2/6-311G** using the GDMA software ${ }^{82}$ and then optimized to reproduce the $a b$ initio QM electrostatic potential from a higher level basis set (e.g., MP2/aug-cc-pVTZ) using TINKER. ${ }^{83}$

Finally, the $\mathrm{Zn}^{2+}$-model compound dimer and water-model compound dimer (Figure 1) interaction energy profiles were evaluated by both the AMOEBA and $a b$ initio methods (at the
Table 2. AMOEBA Force Field Parameters Derived from $A b$ Initio $\mathrm{Zn}^{2+}$ Model Compound Structure and Interaction Energy

$\begin{array}{lcc} & \text { polarizability }\left(\AA^{3}\right) & \mathrm{vdW} r / \varepsilon \\ \mathrm{O} & 0.837 & 1.650 / 0.1120 \\ \mathrm{O}^{-} & 1.600 & 1.850 / 0.1290 \\ \mathrm{~S} & 2.800 & 2.0025 / 0.3550 \\ \mathrm{~S}^{-} & 4.000 & 2.100 / 0.3550 \\ \mathrm{~N} & 1.073 & \\ \mathrm{~N} \text { (aromatic) } & 1.500 & \\ \mathrm{C} & 1.334 & \\ \mathrm{C} \text { (aromatic and COO-) } & 1.750 & \\ \mathrm{H} & 0.496 & \\ \mathrm{H} \text { (aromatic) } & 0.696 & \end{array}$

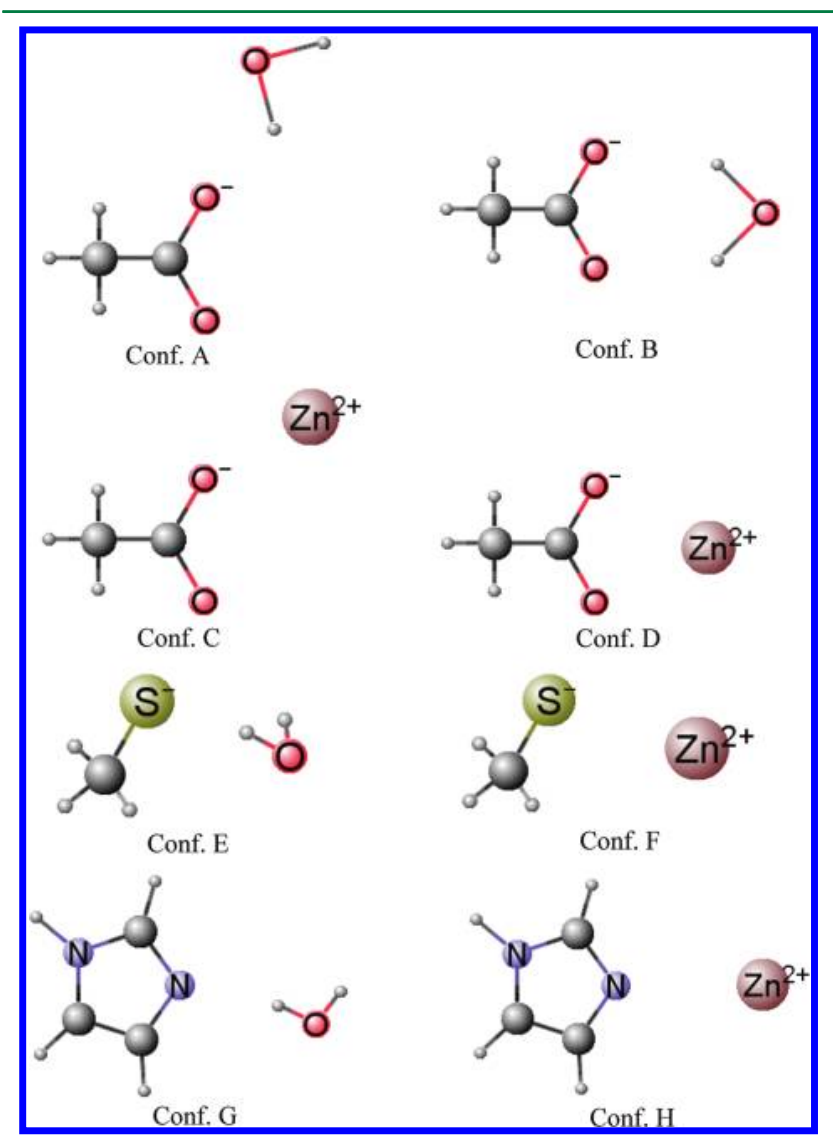

Figure 1. The model systems studied with $\mathrm{QM}$ and AMOEBA.

level of MP2/Aug-cc-pvtz with BSSE corrections) using TINKER $^{83}$ and Gaussian 03, ${ }^{84}$ respectively (see the Supporting Information). Both the $a b$ initio and AMOEBA results were compared at the same geometries, which were minima on the QM surface for different radial variations. The dimer energy was evaluated as the difference between the dimer and monomer energy values, without relaxing the monomer geometry. The missing vdW AMOEBA parameters of the ionic model compounds were fitted to reproduce the $a b$ initio dimer energy, with the electrostatic parameters fixed. The resulting parameters from the model compounds are then transferred to the side chains of the residues for the $\mathrm{Zn}$ protein MD simulations (Table 2).

For the four pyrimidine dicarboxamide inhibitors in MMP complexes (Figure 6), the equilibrium bond and angle values were obtained from the QM (at the level of HF/6-31G*) 


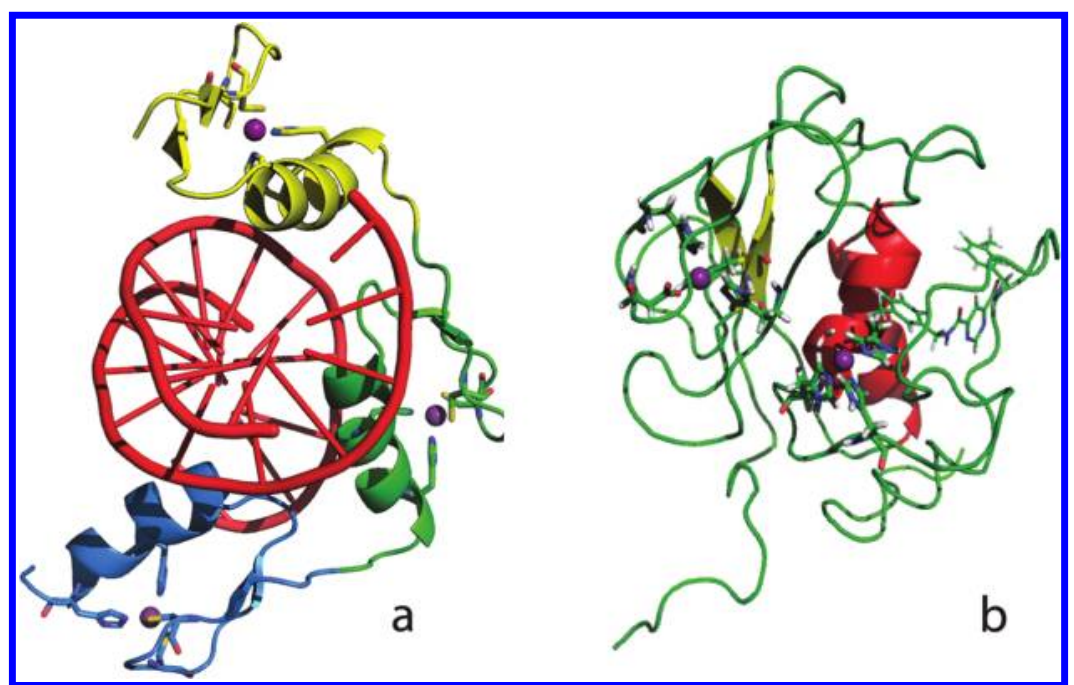

Figure 2. Crystal structures of Zinc-finger protein in complex with DNA (PDB entry: 1AAY, panel a) and MMP13 protein (PDB entry: 1XUD, panel b). In panel a, the DNA is shown in red cartoon representation; the three zinc finger motifs are illustrated in yellow, green, and blue, respectively. In panel b, the $\alpha$ helices are in red, beta sheets are in yellow, and the ligand is in line representation. In both panels, the zinc ions are in purple, and zinc-coordinating residues are in stick representation.

optimized geometry of the ligands. The same procedure described above is used to acquire permanent atomic multipoles. The vdW, bond, angle, out-of-plane, and atomic polarizability parameters of ligands were transferred from the AMOEBA protein force field. The torsion parameters for the rotational bond were fitted to $a b$ initio conformational energy profiles. The parametrization can be automated by using poltype program. ${ }^{85}$

MD Simulation. All of the MD simulations in this study were performed using PMEMD and SANDER in AMBER9 ${ }^{86}$ with the AMOEBA force field. TINKER ${ }^{83}$ was used to prepare the initial systems. Two independent $5 \mathrm{~ns}$ MD simulations for the Zinc-finger protein were performed. The starting conformation was taken from the crystal structure (PDB entry: $1 \mathrm{AAY}^{87}$ ) with DNA removed. The cysteine and histidine residues in the proximity of the $\mathrm{Zn}^{2+}$ ion were deprotonated on the Zn-bound N. On the basis of the crystal structure, HIS69, HIS84, HIS119, HIS123, and HIS129 are deprotonated at $N \varepsilon$ while HIS97 is deprotonated at $N \delta$. The protein was placed in a periodic octahedral water box with at least $15 \AA$ from the solute to the nearest box edge. Each simulation cell has $75 \AA$ on each side, and it contains 9321 AMOEBA water molecules ${ }^{59}$ and 11 $\mathrm{Cl}^{-}$counterions, contributing to a total of 29393 atoms. Two independent $5 \mathrm{~ns} \mathrm{MD}$ simulations for the MMP protein complexes were also performed starting from the crystal structure (PDB entry: 1XUD ${ }^{88}$ ). A similar periodic octahedral water box of $70 \AA$ length on each side was set up with 23470 atoms, including 6938 water molecules. The systems were minimized first and then heated up to $298 \mathrm{~K}$ gradually over 50 ps and then equilibrated for 225 ps under the NPT ensemble. The subsequent $5 \mathrm{~ns} \mathrm{MD}$ simulations were performed in the NVT ensemble, with the density fixed at the NPT-average value and a time step of $1 \mathrm{fs}$. The temperature was maintained at 298 $\mathrm{K}$ using a Berendsen thermostat. ${ }^{89}$ The vdW cutoff was set to $12 \AA$ with long-tail correction applied. In all calculations, the long-range electrostatics were treated using Particle Mesh Ewald (PME) summation. ${ }^{90-92}$ The PME real space cutoff is set to $7 \AA$. The PME calculation used a $90 \times 90 \times 90$ grid and fifth-order $\mathrm{B}$-spline interpolation. The induced dipoles were iterated until the root-mean-square change was below $0.01 \mathrm{D} /$ atom. Atomic coordinates of the simulation system were saved every 0.5 ps.

Binding Free Energy Calculation. The relative binding free energy of four pyrimidine dicarboxamide ligands (Figure 6) to MMP13 was calculated by alchemically transforming one ligand into another in both water and solvated protein complex. A scaling factor $(\lambda)$ is used to divide the perturbation into intermediate steps. For example, ligand $1(\lambda=0)$ to ligand $2(\lambda$ $=1$ ) conversion can be expressed through 11 intermediate steps when $\lambda=\{0,0.1,0.2,0.3,0.4,0.5,0.6,0.7,0.8,0.9,1.0\}$. In both sets of simulations, the electrostatic interactions between ligand 1 and the surroundings were first perturbed to those of ligand 2 and the surroundings by scaling the electrostatic parameters of the two ligands linearly in 5-10 steps depending on the structural similarity of the ligands. Subsequently, the vdW interactions between the ligand and environment were transformed from ligand 1 to 2 in 5-10 steps, followed by valence terms (e.g., changing the equilibrium bond lengths from ligand 1 to 2) in 5-10 steps if applicable. During the decoupling of the vdW interactions, soft-core modifications ${ }^{93}$ were introduced to the buffered $14-7 \mathrm{vdW}$ potential function, to avoid the singularity problem at the end point:

$$
\begin{aligned}
U_{i j}= & \lambda^{n} \varepsilon_{i j} \frac{1.07^{7}}{\left[\alpha(1-\lambda)^{2}+(\rho+0.07)^{7}\right]} \\
& \left(\frac{1.12}{\alpha(1-\lambda)^{2}+\rho^{7}+0.12}-2\right)
\end{aligned}
$$

where the potential well depth $\varepsilon_{i j}$ is in $\mathrm{kcal} / \mathrm{mol}, \rho$ is the effective radius, and $\rho=R_{i j} / R_{i j}{ }^{0} . R_{i j}$ is the actual separation between $i$ and $j$ in $\AA$, and $R_{i j}{ }^{0}$ is the minimum energy distance. $\alpha$ is 0.07 , and $\lambda$ is the scaling factor.

MD simulations were performed at each step along the alchemical pathways for $2 \mathrm{~ns}$ for ligands in protein complexes and $1 \mathrm{~ns}$ for ligands in water. The Bennett Acceptance Ratio 
Table 3. Heterodimer Binding Energies (kcal/mol) and Structures ( $\AA$ ) Computed by AMOEBA and ab Initio QM at Different Configurations (Shown in Figure 1) ${ }^{a}$

\begin{tabular}{|c|c|c|c|c|}
\hline \multirow[b]{2}{*}{ configuration } & \multicolumn{2}{|c|}{$a b$ initio } & \multicolumn{2}{|c|}{ AMOEBA } \\
\hline & distance & $E_{\text {int }}$ & distance & $E_{\text {int }}$ \\
\hline conf. A: $\mathrm{CH} 3 \mathrm{COO}^{-}-$water (external) & $1.65(\mathrm{O} \cdots \mathrm{H})$ & -17.39 & $1.74(\mathrm{O} \cdots \mathrm{H})$ & -17.81 \\
\hline \multirow[t]{3}{*}{ conf. B: $\mathrm{CH} 3 \mathrm{COO}^{-}$-water (bridge) } & $3.18(\mathrm{C} \cdots \mathrm{O})$ & -20.99 & $3.18(\mathrm{C} \cdots \mathrm{O})$ & -22.93 \\
\hline & $1.96(\mathrm{O} 1 \cdots \mathrm{H} 1)$ & & $1.96(\mathrm{O} 1 \cdots \mathrm{H} 1)$ & \\
\hline & $1.96(\mathrm{O} 2 \cdots \mathrm{H} 2)$ & & $1.96(\mathrm{O} 2 \cdots \mathrm{H} 2)$ & \\
\hline conf. C: $\mathrm{CH} 3 \mathrm{COO}^{-}-\mathrm{Zn}^{2+}$ (external) & $1.82(\mathrm{O} \cdots \mathrm{Zn})$ & $-409.81^{b}$ & $1.72(\mathrm{O} \cdots \mathrm{Zn})$ & -356.59 \\
\hline \multirow[t]{2}{*}{ conf. D: $\mathrm{CH} 3 \mathrm{COO}^{-}-\mathrm{Zn}^{2+}(\text { bridge })^{c}$} & $2.25(\mathrm{C} \cdots \mathrm{Zn})$ & $-425.80^{b}$ & $2.10(\mathrm{C} \cdots \mathrm{Zn})$ & -442.30 \\
\hline & $1.90(\mathrm{O} \cdots \mathrm{Zn})$ & & $1.81(\mathrm{O} \cdots \mathrm{Zn})$ & \\
\hline conf. E: $\mathrm{CH} 3 \mathrm{~S}^{-}-$water & $2.14(\mathrm{~S} \cdots \mathrm{H})$ & -16.36 & $2.14(\mathrm{~S} \cdots \mathrm{H})$ & -21.30 \\
\hline conf. F: $\mathrm{CH}_{3} \mathrm{~S}^{-}-\mathrm{Zn}^{2+}$ & $2.24(\mathrm{~S} \cdots \mathrm{Zn})$ & -421.78 & $2.06(\mathrm{~S} \cdots \mathrm{Zn})$ & -391.76 \\
\hline conf. G: imidazole-water & $1.91(\mathrm{~N} \cdots \mathrm{H})$ & -8.20 & $2.11(\mathrm{~N} \cdots \mathrm{H})$ & -8.10 \\
\hline conf. $\mathrm{H}$ : imidazole $-\mathrm{Zn}^{2+}$ & $1.85(\mathrm{~N} \cdots \mathrm{Zn})$ & -175.55 & $1.75(\mathrm{~N} \cdots \mathrm{Zn})$ & -172.25 \\
\hline
\end{tabular}

${ }^{a}$ The $a b$ initio results were obtained at the level of MP2/Aug-cc-pvtz with BSSE, unless otherwise noted. ${ }^{b}$ At the level of B3LYP6-311G**. ${ }^{c}$ With $\mathrm{C}-\mathrm{O}-\mathrm{Zn}$ angle at $150^{\circ}$.

estimator $(\mathrm{BAR})^{94}$ was used to compute the free energy differences between the adjacent intermediate steps:

$$
\begin{aligned}
& \Delta A(j) \lambda_{i} \rightarrow \lambda_{i+1}=-R T \\
& \quad \times \ln \frac{\left\langle 1 /\left[1+\exp \left(\left(E_{\lambda_{i}}-E_{\lambda_{i+1}}+C\right) / R T\right)\right]\right\rangle_{\lambda_{i+1}}}{\left\langle 1 /\left[1+\exp \left(\left(E_{\lambda_{i+1}}-E_{\lambda_{i}}+C\right) / R T\right)\right]\right\rangle_{\lambda_{i}}}+C
\end{aligned}
$$

where $C$ is given by $C=\Delta A(j-1)_{\lambda_{i} \rightarrow \lambda_{i+1}}$ and $j$ is the iteration index. Here, $E_{\lambda i}$ is the total energy of the system evaluated using the simulation snapshots at $\lambda_{i}$, with a dipole convergence of $10^{-6}$ D. $\Delta A$ is solved iteratively until the value of $(\Delta A(j)-$ $\Delta A(j-1))$ is less than $0.01 \mathrm{kcal} / \mathrm{mol}$. While an induced dipole convergence ( $0.01 \mathrm{D}$ per atom) has been used during the simulations for computational efficiency, a tighter convergence of $10^{-6} \mathrm{D}$ per atom is applied to reanalyze the saved snapshots and compute the results. The reweighting is incorporated rigorously into the BAR formula:

$$
\Delta A(j)_{\lambda_{i} \rightarrow \lambda_{i+1}}=-R T \ln \frac{\frac{\left\langle\left[1 /\left(1+\exp \left(\left(E_{\lambda_{i}}-E_{\lambda_{i+1}}+C\right) / R T\right)\right)\right] \times\left[\exp \left(\left(E^{\prime} \lambda_{i+1}-E_{\lambda_{i+1}}\right) / R T\right)\right]\right\rangle_{\lambda_{i+1}^{\prime}}}{\left\langle\exp \left(\left(E^{\prime} \lambda_{i+1}-E_{\lambda_{i+1}}\right) / R T\right)\right\rangle_{\lambda_{i+1}^{\prime}}}}{\frac{\left\langle\left[1 /\left(1+\exp \left(\left(E_{\lambda_{i+1}}-E_{\lambda_{i}}+C\right) / R T\right)\right)\right] \times\left[\exp \left(\left(E^{\prime} \lambda_{i}-E_{\lambda_{i}}\right) / R T\right)\right]\right\rangle_{\lambda_{i}^{\prime}}}{\left\langle\exp \left(\left(^{\prime} \lambda_{i}-E_{\lambda_{i}}\right) / R T\right)\right\rangle_{\lambda_{i}^{\prime}}}}+C
$$

where $E_{\lambda i}^{\prime}$ is the total energy of the system evaluated at $\lambda_{i}$ using a dipole convergence of $0.01 \mathrm{D}$, while $E_{\lambda i}$ indicates the potential energy evaluated using full convergence at $10^{-6} \mathrm{D}$ per atom. $\lambda^{\prime}$ indicates the ensemble obtained using the looser dipole convergence. The reanalysis method was used, and the numerical reliability was verified. The comparison between using the BAR formula (eq 3 ) and using the reweighting BAR formula (eq 4) is discussed in Table 5.

\section{RESULTS AND DISCUSSION}

Dimers of $\mathrm{Zn}^{2+} /$ Water Interacting with Model Compounds. We have first evaluated the $\mathrm{Zn}^{2+}$ or a water molecule interacting with each of the model compounds in both QM and AMOEBA calculations. The goal is to verify and systematically improve the AMOEBA parameters, especially atomic polarizability and vdW radii, of the three model compounds, the acetate anion, the methanthiol anion, and imidazole. The first two ionic compounds were studied for the first time using AMOEBA. The purpose of examining both water and $\mathrm{Zn}^{2+}$ interacting with the same model compound is to avoid any biased changes in the model compound parameters. The AMOEBA atomic multipole parameters for three model compounds were obtained from QM calculations. The atomic polarizability values were mostly transferred from the AMOEBA parameter set, except for a few new types. For the oxygen atom in the acetate anion and the sulfur in $\mathrm{CH}_{3} \mathrm{~S}^{-}$, we found that atomic polarizability values larger than those in neutral molecules are necessary to reproduce the QM and experimental molecular polarizability (Tables 1 and 2). Previously, we also established that the atomic polarizabilities of the aromatic $\mathrm{C}$ and $\mathrm{H}$ in the benzene ring need to be greater than those of $\mathrm{sp}^{3} \mathrm{C}$ and attached $\mathrm{H}$ atoms. ${ }^{64}$ In order to reproduce the $\mathrm{QM}$ dimer energy and minimum-energy structure, increased polarizabilities are also needed for $\mathrm{N}$ and attached $\mathrm{H}$ in imidazole. Larger atomic polarizabilities in anions and aromatic molecules are expected given the excess electrons and more diffused electron clouds. The fact that larger vdW radii are needed for anionic atoms as compared to their neutral counterparts has been reported previously. ${ }^{32,33}$ Larger vdW radii (Table 2) than those in the neutral forms were also obtained by matching AMOEBA with the QM binding energy and geometry for both the $\mathrm{Zn}^{2+}$-model compound and watermodel compound dimers. In Table 3 , the final AMOEBA results are compared with $a b$ initio values, and the binding energy differences and structure deviations are within $10 \%$ for all dimers except for $\mathrm{CH}_{3} \mathrm{~S}^{-}$-water and the bridge configuration of $\mathrm{CH}_{3} \mathrm{COO}^{-}-\mathrm{Zn}^{2+}$. Note that the "constraint" here is that any change in the model compound vdW parameters will affect the $\mathrm{Zn}$-model compound and water-model compound simultaneously. For example, decreasing the oxygen vdW radius 


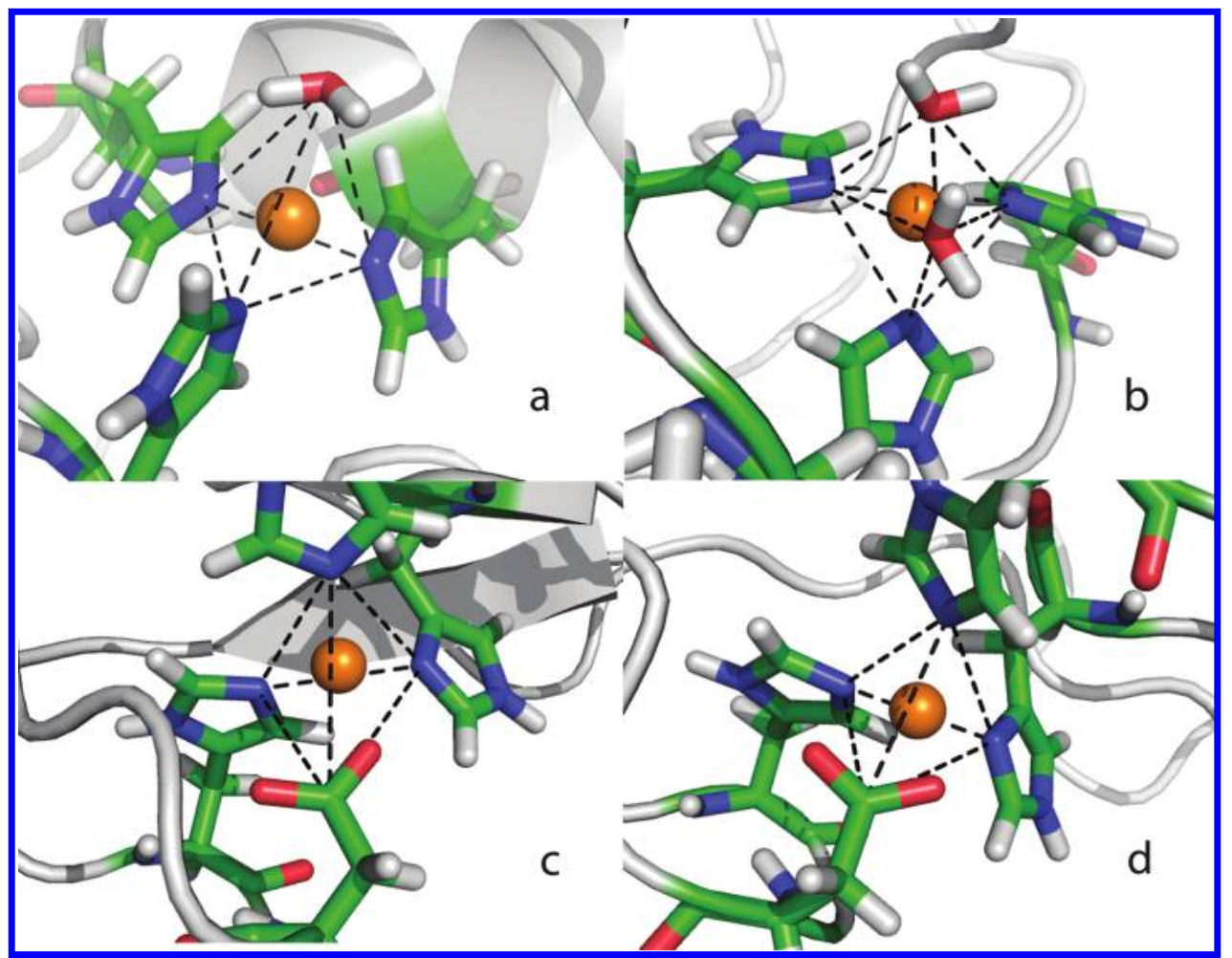

Figure 3. Structure comparison of the two zinc ions in the MMP13 complex (PDB entry: 1XUD): first zinc ion from the crystal structure in the tetrahedron (panel a), first zinc ion from the $5 \mathrm{~ns} \mathrm{MD}$ simulation in trigonal bipyramidal geometry (panel b), second zinc ion from the crystal structure in bidentate tetrahedron (panel c), and second zinc ion from $5 \mathrm{~ns}$ MD simulation in bidentate tetrahedron (panel d).

in $\mathrm{CH}_{3} \mathrm{COO}^{-}$could lead to better agreement for the water$\mathrm{CH}_{3} \mathrm{COO}^{-}$interaction but will also significantly overestimate the $\mathrm{Zn}^{2+}-\mathrm{CH}_{3} \mathrm{COO}^{-}$attraction and pull them even closer than the QM distance. Similar trends were observed previously in fixed charge force fields. ${ }^{95}$ The charge transfer effect accounts for this strongly anticooperative character in the polyligated complexes $\mathrm{Zn}^{2+}$ with anionic ligands, ${ }^{36,37}$ and it should also contribute, along with polarization effects, to the increase of the $\mathrm{Zn}$-ligand distances optimized by quantum chemistry. In addition, it is observed that (Table 3) AMOEBA overestimated the energy gap between "bridge" (both oxygen atoms interacting with $\mathrm{Zn}$ in a bidentate fashion) and "external" (one oxygen forming a close interaction with $\mathrm{Zn}$ ). The AMOEBA dimer energy for the "external" configuration is not as low as that of $a b$ initio. It was noticed from the $a b$ initio energy minimization of the "external" dimer that the $\mathrm{C}-\mathrm{O}$ bond length involving the $\mathrm{O}$ that binds with $\mathrm{Zn}$ was $1.43 \AA$, the other $\mathrm{C}-\mathrm{O}$ bond length was only $1.18 \AA$. The former is essentially a single bond, and the $\mathrm{Zn}^{2+}$ seems to have stabilized one of the "resonance" structures. Our force field has not been implemented to distinguish the two oxygens or the two $\mathrm{C}-\mathrm{O}$ bonds in such cases.

MD Simulations of Zinc Proteins. We have investigated two zinc-binding proteins: (A) a zinc-finger system with three 4-fold coordinated zinc structural sites and (B) a MMP13 complex with one four-coordinated catalytic zinc binding site and another bidentate structural site. The results are presented in Figures 3-5 and are discussed below.

$\mathrm{Zn}^{2+}-\mathrm{Cys}_{2} \mathrm{His}_{2}$ Motif from the $\mathrm{Zn}$ Finger Simulation. Starting from the $\mathrm{X}$-ray structure of a zinc-finger protein (1AAY) containing three zinc ions, two independent $5 \mathrm{~ns}$ simulations have been performed. As we will show later, the change of coordination (due to subtle change in atom

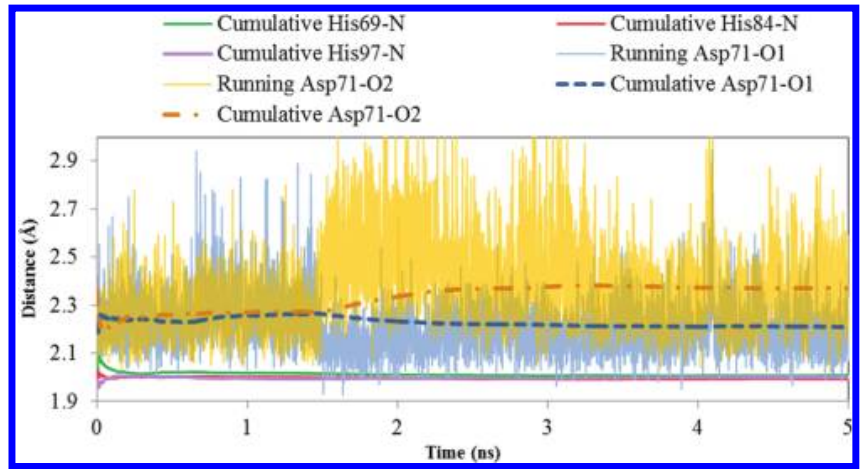

Figure 4. Interatomic distances between $\mathrm{Zn}^{2+}$ and its surrounding ligands during the $5 \mathrm{~ns}$ MD simulation.

polarizability) occurs within a few hundred picoseconds. All three zinc ions are coordinated with two histidines and two cysteines stably throughout the simulations. For all three $\mathrm{Zn}^{2+}$ binding sites, the root-mean-square deviations (RMSDs) of the backbone heavy atoms are $0.6,0.6$, and $0.8 \AA$ from the X-ray structures. The average distances and angles are compared in Table 4. Overall, the zinc coordination structures given by AMOEBA are in very good agreement with the corresponding crystal structures. The average $\mathrm{Zn}-\mathrm{S}$ distance obtained from simulation is $2.13 \pm 0.05 \AA$, which is smaller than the distance of $2.25 \pm 0.07 \AA$ observed in the crystal structure. This slight difference is considered a consequence of optimizing the AMOEBA model against the $a b$ initio calculation shown in Table 3. It is expected that implementing a charge transfer model into our AMOEBA polarizable potential can reproduce a more accurate $\mathrm{Zn}-\mathrm{S}$ distance in both dimer interaction calculation and MD simulation. 


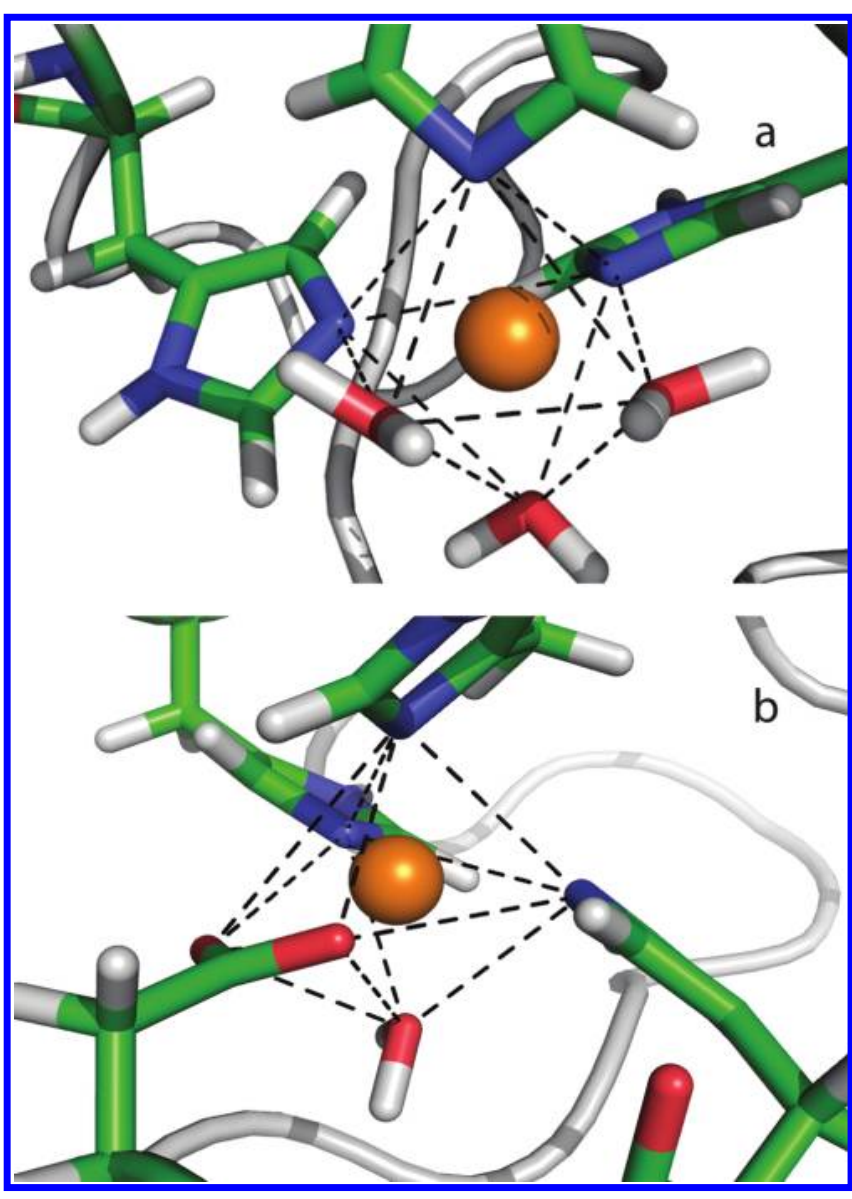

Figure 5. Under-polarization leads to 6-coordinated octahedral geometry for both $\mathrm{His}_{3} \mathrm{H}_{2} \mathrm{O}$ (panel a) and $\mathrm{His}_{3}$ Asp (panel b) Znbinding sites in MMP-13. The corresponding crystal structures are shown in Figure 3.

Table 4. Comparison between MD and Experimental Averaged Zn Distances ( $⿱$ ) and Angles (degree) in the ZnFinger Motif

\begin{tabular}{llcc} 
& & MD simulation & \multicolumn{1}{c}{ X-ray } \\
Zn-finger & $\mathrm{Zn}-\mathrm{S}$ & $2.13(0.05)$ & $2.25(0.07)$ \\
& $\mathrm{Zn}-\mathrm{N}$ & $2.10(0.07)$ & $2.05(0.05)$ \\
& $\mathrm{S}-\mathrm{Zn}-\mathrm{S}$ & $118.5(6.6)$ & $115.8(1.1)$ \\
& $\mathrm{N}-\mathrm{Zn}-\mathrm{N}$ & $93.9(5.2)$ & $103.1(7.3)$ \\
$\mathrm{MMP}$ & $\mathrm{S}-\mathrm{Zn}-\mathrm{N}$ & $106.0(5.3)$ & $110.3(4.5)$ \\
& $\mathrm{Zn}-\mathrm{N}$ & $2.01(0.06)$ & $2.13(0.03)$ \\
& $\mathrm{Zn}-\mathrm{O}_{1}$ & $2.19(0.09)$ & $2.01^{a} ; 1.92(0)^{b}$ \\
& $\mathrm{Zn}-\mathrm{O}_{2}$ & $2.41(0.18)$ & $3.22^{a} ; 2.76(0.13)^{b}$
\end{tabular}

${ }^{a} \mathrm{X}$-ray structure of protein complex $1 \mathrm{XUD} .{ }^{b} \mathrm{X}$-ray structures from $\mathrm{Zn}$ containing protein database survey.

$\mathrm{Zn}^{2+}-\mathrm{His}_{3} \mathrm{H}_{2} \mathrm{O}$ and $\mathrm{Zn}^{2+}-\mathrm{His}_{3} \mathrm{Asp}$ Motif in MMP. We have also modeled a MMP13-ligand complex containing two zinc ions. Two independent 5 ns simulations starting from the X-ray crystal structure (1XUD) have been performed. For the first $\mathrm{Zn}^{2+}$ ion, there are three histidines and one water coordinating to form a tetrahedral structure, as shown in the crystal structure (Figure 3a). The three histidine residues were well maintained during the simulation, with an average $\mathrm{Zn}-\mathrm{N}$ distance of 2.01 $\pm 0.06 \AA$. The water molecules were rather fluid and attempted to enter and leave the zinc coordination sphere during the $5 \mathrm{~ns}$ simulation. Water molecules and zinc were considered as interacting with each other if the distance between them is less than $2.2 \AA$. Two water molecules were observed to interact with the zinc for approximately $75 \%$ of time, contributing to a 5coordinated trigonal bipyramidal geometry (Figure 3b), with one of the water molecules occupying the fourth ligation site, as given in the crystal structure. For $25 \%$ of the simulation time, we observe the 4-coordinated tetrahedral geometry where only one water molecule was coordinating with $\mathrm{Zn}^{2+}$. Considering the fact that more than $30 \%$ of catalytic zinc proteins are 5coordinated, as reported in the literature, ${ }^{13}$ this slight discrepancy seems to be reasonable and could be realistic dynamic behavior that is not captured by the X-ray structure. In addition, a previous $\mathrm{QM} / \mathrm{MM}$ study of MMP2 based on B3LYP/OPLS-AA/PB also suggested that 5-coordination with three HIS residues and two waters is the most stable structure, although it was also pointed out that the energy differences among different coordinations are within the accuracy of DFT methods. ${ }^{96}$

For the second zinc ion, three nitrogen atoms from the His residues plus two bidentate chelation of the Asp oxygen atoms form a bidentate tetrahedral coordination geometry (Figure 3c) in the crystal structure. Such a bidentate tetrahedral geometry was reproduced by our simulation, as shown in Figure 3d, and an alternation of the two oxygen atoms interacting with the zinc ion has been observed. During the 5 ns simulation, the average distance of $\mathrm{Zn}$ coordination for the closer oxygen was $2.21 \pm$ $0.11 \AA$ and that for the further one was $2.38 \pm 0.17 \AA$, as shown in Figure 4; however, during the last $3.5 \mathrm{~ns}$ of simulation, the average distance became $2.19 \pm 0.09 \AA$ and $2.41 \pm 0.18 \AA$, respectively. According to the analysis of the structural consensus of zinc coordination centers, the average distance of the zinc ion and the nearer and farther carboxylate oxygens is $1.92 \pm 0 \AA$ and $2.76 \pm 0.13 \AA$ in structural sites and $1.99 \pm 0.06$ $\AA$ and $2.58 \pm 0.28 \AA$ in catalytic sites, respectively. ${ }^{13}$ It is known that the conventional Coulomb scheme in the nonpolarizable force field has been deficient in describing bidentate chelation of Asp/Glu residues, and our AMOEBA model shows encouraging improvement. Nonetheless, as we discussed earlier, the inability of distinguishing the two oxygen atoms in $\mathrm{COO}^{-}$ by classical force fields results in an underestimation of binding energy of "external configuration" relative to the "bridge" one. Thus, the population of bidentate "bridge" configurations of $\mathrm{Zn} \cdots \mathrm{COO}^{-}$was likely overestimated by the simulation. Additional contributions such as the charge transfer and perhaps charge flow are needed in the force fields in order to capture the bidentate vs external chelation more accurately.

Effect of Polarization on $\mathrm{Zn}^{2+}$ Coordination Geometry. We have demonstrated previously the importance of the polarization effect in treating zinc hydration. ${ }^{18}$ Here, we have also shown that with the induced dipole polarization, the AMOEBA model has yielded zinc coordination structures in very good agreement with the corresponding crystal structures. The $\mathrm{Zn}^{2+}$ parameters so far perform well in a range of different environments, from the water molecules to model compounds to protein complexes, without being "trained" on zinc enzyme complexes.

The importance of polarization effects is also revealed in this study: reduced atomic polarizabilities of the coordinating His residues would drive the coordination geometry to turn to octahedron in less than $1 \mathrm{~ns}$. The coordination number of the zinc ion varies in different protein environments and with different enzyme functionalities; ion coordination numbers also play an important role in the different theories of selectivity. ${ }^{97}$ 
A polarizable force field opens more of a possibility to describe variable zinc coordination reliably and address the different corresponding $\mathrm{Zn}$ enzyme functionalities. It has been reported that the picture of the ion coordination given by $Q M / M M$ simulations differs somewhat from the one provided by classical MD based on nonpolarizable force fields. ${ }^{98}$ The inclusion of polarization effects seems critical. ${ }^{99}$

To probe the effect of electronic polarization on the coordination geometry, we have performed two 2-ns simulations of the MMP-13 complex using a different set of atomic polarizability parameters for atoms on zinc-coordinating histidine rings. The atomic polarizability values were reduced (by $\sim 20-30 \%$ ) to those of nonaromatic elements as reported originally reported by Thole, i.e., $1.073 \AA^{3}$ for C, $1.334 \AA^{3}$ for $\mathrm{N}$, and $0.496 \AA^{3}$ for $\mathrm{H}$. Interestingly, after $\sim 1 \mathrm{~ns} \mathrm{MD}$ simulations, the reduction in polarizability resulted in an octahedral structure for $\mathrm{Zn}^{2+}$ binding with (His) ${ }_{3} \mathrm{H}_{2} \mathrm{O}$ and (His) ${ }_{3}$ Asp (Figure 5), as witnessed in simulations using the fixed-charge force fields. Once the coordination turned to octahedron, it was unable to revert back in our simulations. Thus, underpolarization has yielded 6-coordinated Zn-binding sites, rather than the 4-coordination typically observed in experimental X-ray structures.

It has been reported that, for a nonpolarizable force field, a charge of +2 overestimates the coordination number of the zinc ions and " +1.5 " is the most appropriate for MD simulations. ${ }^{25}$ However, the stabilizing effect due to charge transfer cannot be captured through the "first order" Coulombic interaction of reduced charges. It should also be noted that appropriate vdW parameters for $\mathrm{Zn}^{2+}$ are also important for obtaining the correct coordination of the $\mathrm{Zn}-\mathrm{Cys}_{2} \mathrm{His}_{2}$ binding site, as evidenced from earlier work by Sakharov and Lim. ${ }^{43}$ In this work, we tried to separate the contribution by examining different physical properties. For example, the atomic polarizability was obtained by matching the $a b$ initio molecular polarizability while the vdW parameters were refined using model compound dimer structures and energetics.

Binding Affinity Calculation for Pyrimidine Dicarboxamide Inhibitors Binding with MMP13. With reasonable success in modeling $\mathrm{Zn}$ binding with model compounds and proteins, we have further evaluated the free energy of inhibitors binding to $\mathrm{Zn}$-containing MMP13. Although we are interested in inhibitors that directly chelate to the catalytic zinc ion with zinc binding groups (ZBGs), here we have chosen to study one of the earliest reported sets of nonzinc chelating inhibitors of MMP families. These four highly selective pyrimidine dicarboxamide inhibitors of MMP13 have binding free energies ranging from -7 to $-11 \mathrm{kcal} / \mathrm{mol}$, making an ideal system for evaluating our zinc model in free energy calculations (Figure 6). Generally, the nonzinc chelating inhibitors can overcome the nonselective toxicity. The zinc ion does not "directly" interact with these inhibitors, but the shortest distances between the $\mathrm{Zn}$ ion and the inhibitor heavy atoms is only $4.7 \AA$. To compute the relative binding free energy among the four ligands, ligands 2 through 3 were alchemically transformed from ligand 4 , and ligand 2 was transformed into ligand 1 . The experimental binding free energies are based on inhibition constants determined by isothermal titration calorimetry under various assay conditions. ${ }^{100}$

The calculated relative binding free energies are in agreement with experimental measurements (Table 5) with a RMSD of $0.72 \mathrm{kcal} / \mathrm{mol}$. The calculated relative binding free energies have been offset by the experimental binding free energy of

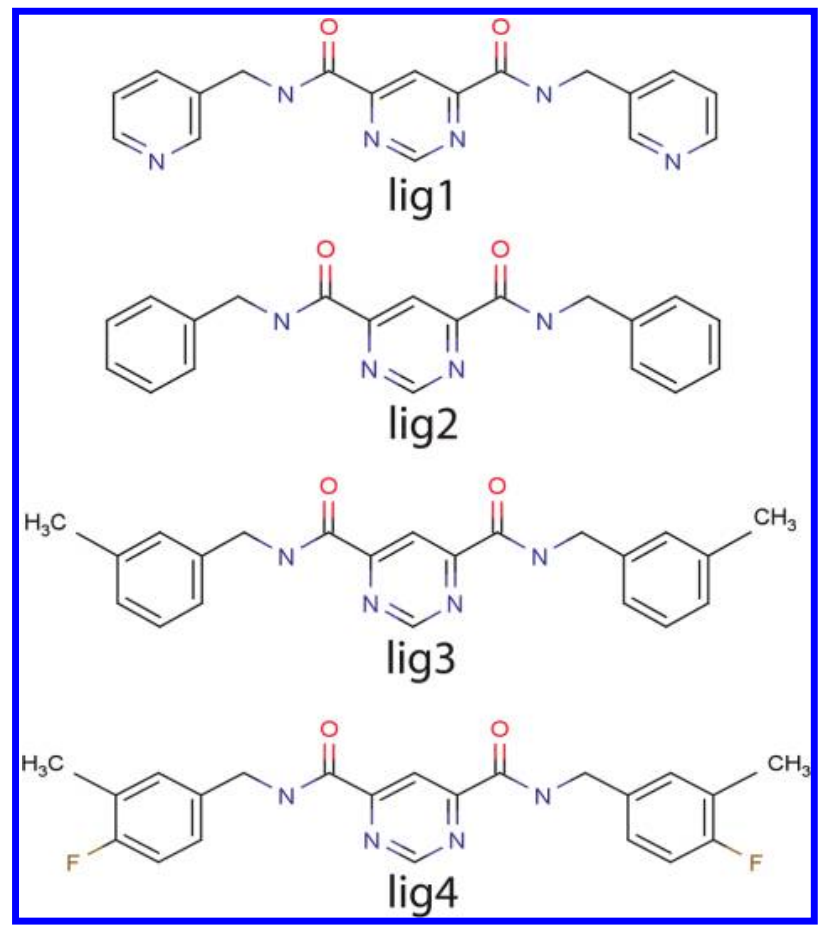

Figure 6. Pyrimidine dicarboxamide inhibitors binding with MMP-13.

MMP13-ligand 4 and plotted in Figure 7. A correlation coefficient $(R)$ of 0.95 between the calculated and experimental binding free energy was obtained. ${ }^{100}$ Using BAR and BAR reweighting procedures gave us similar merits.

Despite the limited data points, we observe a noticeable correlation between binding free energy and polarizability, i.e., the stronger the molecular polarizability, the more favorable the binding affinity is. For ligands 1, 2, 3, and 4, the molecular polarizability values are $28.4,29.5,32.3$, and $32.4 \AA^{3}$, respectively, and the experimental binding affinities are $-7.07,-8.73,-9.75$, and $-11.05 \mathrm{kcal} / \mathrm{mol}$. We have previously reported a similar trend for the trypsin-benzamidine ligands. ${ }^{101}$

To probe the role of the zinc electrostatics on the binding, we performed a virtual experiment where the zinc ion charge was switched off from +2 to 0 . The relative binding free energies among the four inhibitors were re-evaluated by using the same $\mathrm{MD}$ trajectories obtained from $\mathrm{Zn}^{2+}$ simulations. Removing the $\mathrm{Zn}^{2+}+2$ charge led to a significant and consistent overestimation of relative binding free energy differences (Figure 7). The RMSD between experimental and calculated relative binding affinity became $\sim 2.2 \mathrm{kcal} / \mathrm{mol}$. It suggests that the effect of zinc charge does not "cancel" between the different inhibitors binding to MMP13. Instead, the presence of $\mathrm{Zn}^{2+}$ seems to minimize the affinity gaps among the tested inhibitors.

We also performed an additional test where the polarization due to the zinc ion is turned off in the system but the +2 charge on zinc was kept. The relative binding free energies were again re-evaluated using the same MD trajectories (Table 5). Compared to the "BAR" scheme with full parameters, setting the $\mathrm{Zn}$ charge to 0 generated less favorable relative binding free energies, and turning off $\mathrm{Zn}$ polarization seemed to generate more favorable relative binding free energies, which is consistent with the findings of our previous study of trypsinbenzamidine binding. ${ }^{66}$ More interestingly, neglecting the polarization effect of the zinc ion led to a deviated ranking 
Table 5. Relative Binding Free Energies from Alchemical Perturbation Calculations (kcal/mol $)^{a}$

\begin{tabular}{|c|c|c|c|c|c|c|c|c|c|c|c|c|c|}
\hline & \multicolumn{3}{|c|}{ BAR (eq 3) } & \multicolumn{3}{|c|}{ reweighting BAR (eq 4) } & \multicolumn{3}{|c|}{ BAR with $\mathrm{Zn}$ charge set to 0} & \multicolumn{3}{|c|}{$\begin{array}{l}\text { BAR without polarization by } \\
\qquad \mathrm{Zn}^{2+}\end{array}$} & $\begin{array}{l}\text { experiment } \\
\text { results }\end{array}$ \\
\hline & $\Delta G_{\text {lig-wat }}$ & $\Delta G_{\text {lig-pro }}$ & $\overline{\Delta \Delta G}$ & $\Delta G_{\text {lig-wat }}$ & $\Delta G_{\text {lig-pro }}$ & $\overline{\Delta \Delta G}$ & $\Delta G_{\text {lig-wat }}$ & $\Delta G_{\text {lig-pro }}$ & $\overline{\Delta \Delta G}$ & $\Delta G_{\text {lig-wat }}$ & $\Delta G_{\text {lig-pro }}$ & $\overline{\Delta \Delta G}$ & $\Delta \Delta G_{\operatorname{expr}}^{b}$ \\
\hline $4 \rightarrow 3$ & 4.14 & 5.52 & 1.38 & 4.14 & 5.55 & 1.41 & 4.14 & 5.82 & 1.68 & 4.14 & 5.29 & 1.15 & 1.30 \\
\hline $4 \rightarrow 2$ & 11.94 & 13.45 & 1.51 & 13.47 & 15.15 & 1.68 & 11.94 & 15.01 & 3.07 & 11.94 & 13.02 & 1.08 & 2.32 \\
\hline $2 \rightarrow 1$ & -10.07 & -9.36 & 0.71 & -9.77 & -9.30 & 0.46 & -10.07 & -5.52 & 4.55 & -10.07 & -10.85 & -0.62 & 1.66 \\
\hline
\end{tabular}

${ }^{a}$ In the BAR procedure, the simulation was performed using an induced-dipole convergence of $0.01 \mathrm{D}$ per atom, and the free energy was evaluated with a tighter convergence $\left(10^{-6}\right)$ using eq 3 . The reweighting BAR introduces a rigorous reweighting due to the different polarization convergence based on eq $4 .{ }^{b} \operatorname{Ref} 100$.

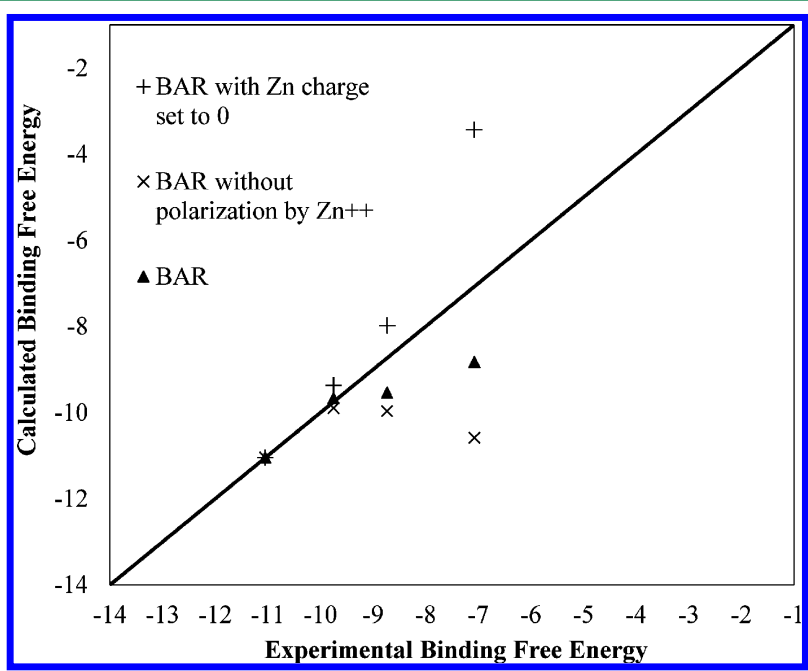

Figure 7. Comparison of calculated and experimental relative binding free energies $(\mathrm{kcal} / \mathrm{mol})$. Ligands $4,3,2$, and 1 can be identified from the $x$ axis in order from left to right, respectively, with the corresponding experimental binding free energies $-11.05,-9.75$, -8.73 , and $-7.07 \mathrm{kcal} / \mathrm{mol}$.

order. This suggests that the polarization effect due to the zinc ion is not systematic but inhibitor-dependent. This would make it difficult for nonpolarizable force fields to capture the polarization effect implicitly, e.g., by scaling the ligand charges. The decisive role of polarization in enabling a correct ranking of competing inhibitors to a given protein target has also been demonstrated recently, such as in the complexes of pyrrolopyrimidine inhibitors to the FAK kinase ${ }^{102}$ and mannose phosphate/malonate surrogates to the phosphomannoisomerase $\mathrm{Zn}$-metalloenzyme. ${ }^{103}$

\section{CONCLUSION}

Metal ions play indispensible roles in protein structure and function, as nearly one-third of all proteins contain metal ions. Understanding the $\mathrm{Zn}$-protein binding, in particular, the factors governing specificity and coordination geometry, is crucial for the development of novel ligands for existing $\mathrm{Zn}$ binding sites as well as the de novo design of new $\mathrm{Zn}$-binding proteins.

Polarizable force fields hold the promise for treating metal ions in proteins in an effective way, by explicitly taking into account the polarization and potentially the charge-transfer effects. In the AMOEBA polarizable potential, the polarization effect is treated via atomic dipole induction. In a previous study, we have shown that charge transfer effect in $\mathrm{Zn}^{2+}$ binding clusters diminishes moving from the gas-phase toward the condensed-phase and to some extent can be incorporated into the dipole polarization. ${ }^{18}$ In this study, we have examined $\mathrm{Zn}^{2+}$ interacting with common ligands in a protein environment. We have refined the atomic polarizability and vdW parameters of a few atom types in the His, charged Cys, and Asp residue side chains by assessing their interactions with $\mathrm{Zn}^{2+}$ and the water molecule, respectively. Extensive MD simulations of two zinccontaining enzyme systems with different coordinating ligands, including a bidentate tetrahedral binding site, has yielded reasonable zinc coordination geometry and binding distances in comparison with the X-ray crystal structures. More interestingly, we found that the coordination geometry is very sensitive to the polarizabilities of the coordinating ligands. Underpolarization leads to 6-coordination instead of the 4coordination that is typically observed experimentally.

The relative binding free energies of four MMP13 inhibitors have been calculated to be in good agreement with experimental measurements. While there is a moderate separation distance between the zinc ion and the inhibitors, the +2 net charge on zinc has a strong influence on the inhibitor relative binding affinities. The polarizing field from the zinc ion also contributes to the binding energetics but in an inhibitor-dependent way, as expected from the many-bodied nature of the polarization effect. The AMOEBA polarizable force field has demonstrated its capacity for accurate description of $\mathrm{Zn}$-protein interactions. The results obtained in this study encourage a broader investigation of ligand binding to metalloproteins using polarizable force fields, including those directly involving metal ions at the binding site. Meanwhile, efforts to include the short-range charge transfer and penetration functionalities into the AMOEBA polarizable multipole model is ongoing, which is expected to further improve our ability to model complex ion-protein interactions.

\section{ASSOCIATED CONTENT}

\section{S Supporting Information}

The comparative tables comparing $a b$ initio and AMOEBA. This information is available free of charge via the Internet at http://pubs.acs.org.

\section{AUTHOR INFORMATION}

\section{Corresponding Author}

*E-mail: pren@mail.utexas.edu.

\section{Notes}

The authors declare no competing financial interest.

\section{ACKNOWLEDGMENTS}

We thank the National Institute of General Medical Sciences (R01GM079686) and Robert A. Welch foundation (F-1691) for support. The HPC resources were provided by the National Science Foundation through TeraGrid and the Texas Advanced Computing Center (TACC) under grant number TG- 
MCB100057. W.Y. is grateful for the funding support (MCB 0919983) by National Science Foundation.

\section{REFERENCES}

(1) Tainer, J. A.; Roberts, V. A.; Getzoff, E. D. Curr. Opin. Biotechnol. 1991, 2, 582-591.

(2) Wriggers, W.; Mehler, E.; Pitici, F.; Weinstein, H.; Schulten, K. Biophys. J. 1998, 74, 1622-1639.

(3) Xiao, B.; Heath, R.; Saiu, P.; Leiper, F. C.; Leone, P.; Jing, C.; Walker, P. A.; Haire, L.; Eccleston, J. F.; Davis, C. T.; Martin, S. R.; Carling, D.; Gamblin, S. J. Nature 2007, 449, 496-U414.

(4) Lee, S. B.; Warthaka, M.; Yan, C. L.; Kaoud, T. S.; Piserchio, A.; Ghose, R.; Ren, P. Y.; Dalby, K. N. PLoS One 2011, 6.

(5) Ivano Bertini, A. S.; Sigel, H. Handbook on metalloproteins 2001.

(6) Christianson, D. W. Adv. Protein Chem. 1991, 42, 281-355.

(7) Parkin, G. Chem. Rev. 2004, 104, 699-767.

(8) Lipscomb, W. N.; Strater, N. Chem. Rev. 1996, 96, 2375-2433.

(9) Wilcox, D. E. Chem. Rev. 1996, 96, 2435-2458.

(10) Murakami, M.; Hirano, T. Cancer Sci. 2008, 99, 1515-1522.

(11) Chaturvedi, U. C.; Shrivastava, R. FEMS Immunol. Med. Microbiol. 2005, 43, 105-114.

(12) Lee, Y. M.; Lim, C. J. Mol. Biol. 2008, 379, 545-553.

(13) Patel, K.; Kumar, A.; Durani, S. Biochim. Biophys. Acta, Proteins Proteomics 2007, 1774, 1247-1253.

(14) Vallee, B. L.; Falchuk, K. H. Physiol. Rev. 1993, 73, 79-118.

(15) Raha, K.; Merz, K. M. J. Am. Chem. Soc. 2004, 126, 1020-1021.

(16) Fatmi, M. Q.; Hofer, T. S.; Rode, B. M. Phys. Chem. Chem. Phys. 2010, 12, 9713-9718.

(17) Fatmi, M. Q.; Hofer, T. S.; Randolf, B. R.; Rode, B. M. J. Phys. Chem. B 2007, 111, 151-158.

(18) Wu, J. C.; Piquemal, J. P.; Chaudret, R.; Reinhardt, P.; Ren, P. Y. J. Chem. Theory Comput. 2010, 6, 2059-2070.

(19) Wang, C.; Vernon, R.; Lange, O.; Tyka, M.; Baker, D. Protein Sci. 2010, 19, 494-506.

(20) Donini, O. A. T.; Kollman, P. A. J. Med. Chem. 2000, 43, 41804188

(21) Merz, K. M.; Kollman, P. A. J. Am. Chem. Soc. 1989, 111, 56495658 .

(22) Demoulin, D.; Pullman, A. Theor. Chim. Acta 1978, 49, 161181.

(23) Kothekar, V.; Pullman, A.; Demoulin, D. Int. J. Quantum Chem. 1978, 14, 779-791.

(24) Stote, R. H.; Karplus, M. Proteins: Struct., Funct., Genet. 1995, 23, $12-31$.

(25) Koca, J.; Zhan, C. G.; Rittenhouse, R. C.; Ornstein, R. L. J. Comput. Chem. 2003, 24, 368-378.

(26) Hoops, S. C.; Anderson, K. W.; Merz, K. M. J. Am. Chem. Soc. 1991, 113, 8262-8270.

(27) Toba, S.; Damodaran, K. V.; Merz, K. M. J. Med. Chem. 1999, $42,1225-1234$

(28) Zhang, W.; Hou, T. J.; Qiao, X. B.; Huai, S.; Xu, X. J. J. Mol. Model. 2004, 10, 112-120.

(29) Roe, R. R.; Pang, Y. P. J. Mol. Model. 1999, 5, 134-140.

(30) Calimet, N.; Simonson, T. J. Mol. Graphics Modell. 2006, 24, 404-411.

(31) Gresh, N.; Derreumaux, P. J. Phys. Chem. B 2003, 107, 48624870.

(32) Gresh, N.; Piquemal, J. P.; Krauss, M. J. Comput. Chem. 2005, 26, 1113-1130.

(33) Gresh, N. J. Comput. Chem. 1995, 16, 856-882.

(34) Garmer, D. R.; Gresh, N.; Roques, B. P. Proteins: Struct., Funct., Bioinf. 1998, 31, 42-60.

(35) Gresh, N.; Roques, B. P. Biopolymers 1997, 41, 145-164.

(36) Tiraboschi, G.; Gresh, N.; Giessner-Prettre, C.; Pedersen, L. G.; Deerfield, D. W. J. Comput. Chem. 2000, 21, 1011-1039.

(37) Tiraboschi, G.; Roques, B. P.; Gresh, N. J. Comput. Chem. 1999, 20, 1379-1390.

(38) Antony, J.; Gresh, N.; Olsen, L.; Hemmingsen, L.; Schofield, C. J.; Bauer, R. J. Comput. Chem. 2002, 23, 1281-1296.
(39) Antony, J.; Piquemal, J. P.; Gresh, N. J. Comput. Chem. 2005, 26, 1131-1147.

(40) Jenkins, L. M. M.; Hara, T.; Durell, S. R.; Hayashi, R.; Inman, J. K.; Piquemal, J. P.; Gresh, N.; Appella, E. J. Am. Chem. Soc. 2007, 129, 11067-11078.

(41) Roux, C.; Gresh, N.; Perera, L. E.; Piquemal, J. P.; Salmon, L. J. Comput. Chem. 2007, 28, 938-957.

(42) Roux, C.; Bhatt, F.; Foret, J.; de Courcy, B.; Gresh, N.; Piquemal, J. P.; Jeffery, C. J.; Salmon, L. Proteins: Struct., Funct., Bioinf. 2011, 79, 203-220.

(43) Sakharov, D. V.; Lim, C. J. Am. Chem. Soc. 2005, 127, 49214929.

(44) Urnov, F. D.; Miller, J. C.; Lee, Y. L.; Beausejour, C. M.; Rock, J. M.; Augustus, S.; Jamieson, A. C.; Porteus, M. H.; Gregory, P. D.; Holmes, M. C. Nature 2005, 435, 646-651.

(45) Li, W. F.; Zhang, J.; Wang, J.; Wang, W. J. Am. Chem. Soc. 2008, $130,892-900$

(46) Winum, J. Y.; Scozzafava, A.; Montero, J. L.; Supuran, C. T. Curr. Pharm. Des. 2008, 14, 615-621.

(47) Hu, J. L.; Van den Steen, P. E.; Sang, Q. X. A.; Opdenakker, G. Nat. Rev. Drug Discovery 2007, 6, 480-498.

(48) Durrant, J. D.; de Oliveira, C. A. F.; McCammon, J. A. J. Mol. Recognit. 2010, 23, 173-182.

(49) Dejonckheere, E.; Libert, C.; Vandenbroucke, R. Drug Discovery Today 2011, 16, 762-778.

(50) Sang, Q. X. A.; Jin, Y. H.; Newcomer, R. G.; Monroe, S. C.; Fang, X. X.; Hurst, D. R.; Lee, S.; Cao, Q.; Schwartz, M. T. A. Curr. Top. Med. Chem. 2006, 6, 289-316.

(51) Durrant, J. D.; de Oliveira, C. A. F.; McCammon, J. A. Chem. Biol. Drug Des. 2011, 78, 191-198.

(52) Cuniasse, P.; Devel, L.; Makaritis, A.; Beau, F.; Georgiadis, D.; Matziari, A.; Yiotakis, A.; Dive, V. Biochimie 2005, 87, 393-402.

(53) Jacobsen, E. J.; Mitchell, M. A.; Hendges, S. K.; Belonga, K. L.; Skaletzky, L. L.; Stelzer, L. S.; Lindberg, T. J.; Fritzen, E. L.; Schostarez, H. J.; O’Sullivan, T. J.; Maggiora, L. L.; Stuchly, C. W.; Laborde, A. L.; Kubicek, M. F.; Poorman, R. A.; Beck, J. M.; Miller, H. R.; Petzold, G. L.; Scott, P. S.; Truesdell, S. E.; Wallace, T. L.; Wilks, J. W.; Fisher, C.; Goodman, L. V.; Kaytes, P. S.; Ledbetter, S. R.; Powers, E. A.; Vogeli, G.; Mott, J. E.; Trepod, C. M.; Staples, D. J.; Baldwin, E. T.; Finzel, B. C. J. Med. Chem. 1999, 42, 1525-1536.

(54) Dublanchet, A. C.; Ducrot, P.; Andrianjara, C.; O’Gara, M.; Morales, R.; Compere, D.; Denis, A.; Blais, S.; Cluzeau, P.; Courte, K.; Hamon, J.; Moreau, F.; Prunet, M. L.; Tertre, A. Bioorg. Med. Chem. Lett. 2005, 15, 3787-3790.

(55) Pochetti, G.; Montanari, R.; Gege, C.; Chevrier, C.; Taveras, A. G.; Mazza, F. J. Med. Chem. 2009, 52, 1040-1049.

(56) Ren, P. Y.; Ponder, J. W. J. Comput. Chem. 2002, 23, 14971506.

(57) Halgren, T. A. J. Am. Chem. Soc. 1992, 114, 7827-7843.

(58) Ponder, J. W.; Wu, C. J.; Ren, P. Y.; Pande, V. S.; Chodera, J. D.; Schnieders, M. J.; Haque, I.; Mobley, D. L.; Lambrecht, D. S.; DiStasio, R. A.; Head-Gordon, M.; Clark, G. N. I.; Johnson, M. E.; HeadGordon, T. J. Phys. Chem. B 2010, 114, 2549-2564.

(59) Ren, P. Y.; Ponder, J. W. J. Phys. Chem. B 2003, 107, 59335947.

(60) Ren, P. Y.; Ponder, J. W. J. Phys. Chem. B 2004, 108, 1342713437.

(61) Grossfield, A.; Ren, P. Y.; Ponder, J. W. J. Am. Chem. Soc. 2003, $125,15671-15682$.

(62) Jiao, D.; King, C.; Grossfield, A.; Darden, T. A.; Ren, P. Y. J. Phys. Chem. B 2006, 110, 18553-18559.

(63) Piquemal, J. P.; Perera, L.; Cisneros, G. A.; Ren, P. Y.; Pedersen, L. G.; Darden, T. A. J. Chem. Phys. 2006, 125.

(64) Ren, P. Y.; Wu, C. J.; Ponder, J. W. J. Chem. Theory Comput. 2011, 7, 3143-3161.

(65) Shi, Y.; Wu, C. J.; Ponder, J. W.; Ren, P. Y. J. Comput. Chem. 2011, 32, 967-977.

(66) Jiao, D.; Golubkov, P. A.; Darden, T. A.; Ren, P. Proc. Natl. Acad. Sci. U. S. A. 2008, 105, 6290-6295. 
(67) Jiao, D.; Zhang, J. J.; Duke, R. E.; Li, G. H.; Schnieders, M. J.;

Ren, P. Y. J. Comput. Chem. 2009, 30, 1701-1711.

(68) Schnieders, M. J.; Fenn, T. D.; Pande, V. S. J. Chem. Theory Comput. 2011, 7, 1141-1156.

(69) Fenn, T. D.; Schnieders, M. J.; Brunger, A. T.; Pande, V. S. Biophys. J. 2010, 98, 2984-2992.

(70) Schnieders, M. J.; Fenn, T. D.; Pande, V. S.; Brunger, A. T. Acta Crystallogr., Sect. D: Biol. Crystallogr. 2009, 65, 952-965.

(71) Clavaguera, C.; Dognon, J. P.; Pyykko, P. Chem. Phys. Lett. 2006, 429, 8-12.

(72) Clavaguera, C.; Pollet, R.; Soudan, J. M.; Brenner, V.; Dognon, J. P. J. Phys. Chem. B 2005, 109, 7614-7616.

(73) Clavaguera, C.; Sansot, E.; Calvo, F.; Dognon, J. P. J. Phys. Chem. B 2006, 110, 12848-12851.

(74) Rogers, D. M.; Beck, T. L. J. Chem. Phys. 2010, 132.

(75) Tuma, L.; Jenicek, D.; Jungwirth, P. Chem. Phys. Lett. 2005, 411, $70-74$.

(76) Zhao, Z.; Rogers, D. M.; Beck, T. L. J. Chem. Phys. 2010, 132. (77) Jiang, J. L.; Wu, Y. B.; Wang, Z. X.; Wu, C. J. Chem. Theory Comput. 2010, 6, 1199-1209.

(78) Kaminsky, J.; Jensen, F. J. Chem. Theory Comput. 2007, 3, 17741788.

(79) Liang, T.; Walsh, T. R. Phys. Chem. Chem. Phys. 2006, 8, 44104419.

(80) Liang, T.; Walsh, T. R. Mol. Simul. 2007, 33, 337-342.

(81) Burnham, C. J.; Li, J. C.; Xantheas, S. S.; Leslie, M. J. Chem. Phys. 1999, 110, 4566-4581.

(82) Stone, A. J. GDMA. http://www-stone.ch.cam.ac.uk/ documentation/gdma/ (accessed: May 2001, 2011).

(83) Ponder, J. W. Tinker Molecular Modeling. http://dasher.wustl. edu/tinker/ (accessed: July 2, 2010).

(84) Frisch, M. J.; Trucks, G. W.; Schlegel, H. B.; Scuseria, G. E.; Robb, M. A.; Cheeseman, J. R.; Montgomery, J. A., Jr.; Vreven, T.; Kudin, K. N.; Burant, J. C.; Millam, J. M.; Iyengar, S. S.; Tomasi, J.; Barone, V.; Mennucci, B.; Cossi, M.; Scalmani, G.; Rega, N.; Petersson, G. A.; Nakatsuji, H.; Hada, M.; Ehara, M.; Toyota, K.; Fukuda, R.; Hasegawa, J.; Ishida, M.; Nakajima, T.; Honda, Y.; Kitao, O.; Nakai, H.; Klene, M.; Li, X.; Knox, J. E.; Hratchian, H. P.; Cross, J. B.; Bakken, V.; Adamo, C.; Jaramillo, J.; Gomperts, R.; Stratmann, R. E.; Yazyev, O.; Austin, A. J.; Cammi, R.; Pomelli, C.; Ochterski, J. W.; Ayala, P. Y.; Morokuma, K.; Voth, G. A.; Salvador, P.; Dannenberg, J. J.; Zakrzewski, V. G.; Dapprich, S.; Daniels, A. D.; Strain, M. C.; Farkas, O.; Malick, D. K.; Rabuck, A. D.; Raghavachari, K.; Foresman, J. B.; Ortiz, J. V.; Cui, Q.; Baboul, A. G.; Clifford, S.; Cioslowski, J.; Stefanov, B. B.; Liu, G.; Liashenko, A.; Piskorz, P.; Komaromi, I.; Martin, R. L.; Fox, D. J.; Keith, T.; Al-Laham, M. A.; Peng, C. Y.; Nanayakkara, A.; Challacombe, M.; Gill, P. M. W.; Johnson, B.; Chen, W.; Wong, M. W.; Gonzalez, C.; Pople, J. A. Gaussian 03; Gaussian, Inc.: Pittsburgh, PA, 2003.

(85) Wu, J. C.; Chattree, G.; Ren, P. Y. Theor. Chem. Acc. 2011.

(86) Case, D. A.; Cheatham, T. E.; Darden, T.; Gohlke, H.; Luo, R.; Merz, K. M.; Onufriev, A.; Simmerling, C.; Wang, B.; Woods, R. J. J. Comput. Chem. 2005, 26, 1668-1688.

(87) ElrodErickson, M.; Rould, M. A.; Nekludova, L.; Pabo, C. O. Structure 1996, 4, 1171-1180.

(88) Wasserman, Z. R. Chem. Biol. 2005, 12, 143-144.

(89) Berendsen, H. J. C.; Postma, J. P. M; Vangunsteren, W. F.; Dinola, A.; Haak, J. R. J. Chem. Phys. 1984, 81, 3684-3690.

(90) Essmann, U.; Perera, L.; Berkowitz, M. L.; Darden, T.; Lee, H.; Pedersen, L. G. J. Chem. Phys. 1995, 103, 8577-8593.

(91) Darden, T.; York, D.; Pedersen, L. J. Chem. Phys. 1993, 98, 10089-10092.

(92) Sagui, C.; Darden, T. A. Annu. Rev. Biophys. Biomol. Struct. 1999, $28,155-179$.

(93) Beutler, T. C.; Mark, A. E.; Vanschaik, R. C.; Gerber, P. R.; van Gunsteren, W. F. Chem. Phys. Lett. 1994, 222, 529-539.

(94) Bennett, C. H. J. Comput. Phys. 1976, 22, 245-268.

(95) Brandt, E. G.; Hellgren, M.; Brinck, T.; Bergman, T.; Edholm, O. Phys. Chem. Chem. Phys. 2009, 11, 975-983.
(96) Diaz, N.; Suarez, D.; Sordo, T. L. J. Phys. Chem. B 2006, 110, 24222-24230.

(97) Varma, S.; Rempe, S. B. Biophys. J. 2007, 93, 1093-1099.

(98) Bucher, D.; Guidoni, L.; Carloni, P.; Rothlisberger, U. Biophys. J. 2010, 98, L47-L49.

(99) Bucher, D.; Rothlisberger, U. J. Gen. Physiol. 2010, 135, 549554.

(100) Engel, C. K.; Pirard, B.; Schimanski, S.; Kirsch, R.; Habermann, J.; Klingler, O.; Schlotte, V.; Weithmann, K. U.; Wendt, K. U. Chem. Biol. 2005, 12, 181-189.

(101) Shi, Y.; Jiao, D. A.; Schnieders, M. J.; Ren, P. Y. Annu. Int. Conf. IEEE Eng. Med. Biol. Soc. 2009, 1, 2328-2331.

(102) de Courcy, B.; Piquemal, J. P.; Garbay, C.; Gresh, N. J. Am. Chem. Soc. 2010, 132, 3312-3320.

(103) Gresh, N.; de Courcy, B.; Piquemal, J. P.; Foret, J.; CourtiolLegourd, S.; Salmon, L. J. Phys. Chem. B 2011, 115, 8304-8316.

(104) Voisin, C.; Cartier, A.; Rivail, J. L. J. Phys. Chem. 1992, 96, $7966-7971$.

(105) Zope, R. R.; Baruah, T.; Pederson, M. R.; Dunlap, B. I. Int. J. Quantum Chem. 2008, 108, 307-317.

(106) Calderbank, K. E.; Calvert, R. L.; Lukins, P. B.; Ritchie, G. L. D. Aust. J. Chem. 1981, 34, 1835-1844.

(107) Carles, S.; Lecomte, F.; Schermann, J. P.; Desfrancois, C. J. Phys. Chem. A 2000, 104, 10662-10668. 